\title{
THE DESIRABILITY OF CONSOLIDATING THE UNIFORM COMMERCIAL STATUTES
}

\author{
R.AIPH S. BAUER
}

It is a matter of common knowledge among lawyers that the uniform commercial statutes have not brought about the desired certainty of decision and that they have not produced a condition that even closely approaches uniformity among the states in any important branch of the law, and it is known to many that among the causes of the present confusion in the construction of the uniform statutes is a failure to understand the essential unity of a given concept common to all of such statutes or to several of them. Lack of comprehension of the fact, for instance, that the same general principles as to voidness or voidability of a transaction govern in sales as in negotiable instruments, has caused: first, needless difficulties in the study of the commercial law subjects by law students; second, erroneous decisions by courts, and third, as a result of these first two conditions, an added number of cases conflicting with each other and with principle, and increasing the lack of uniformity in the administration of our "uniform" statutes. By unifying or consolidating into one general commercial statute the Negotiable Instruments Law; the Sales Act, the Conditional Sales Act, the Bills of Lading Act, the Warehouse Receipts Act, and the Stock Transfer Act, would it not be possible to eliminate some of the present difficulties?

These statutes contain a considerable number of principles that are common to all of them. Unity of such a concept as "good faith," "fraud," "duress," "purchaser," or "value" is, however, evident to far too few students, for, in the ordinary pursuit of study in a law class too frequently a student learns of "good faith" or any other concept as if it were a technical term peculiar to negotiable instruments and merely sees it defined and explained in its operation by several cases in that one subject. Later he approaches the same terms and the same identical concepts, in sales and other subjects, as if they were entirely new and only slightly analogous to the same terms and concepts already studied. Some 
will argue that any good student ought to sense unity of concept in such instances, and we may grant that this is true; but, as actual facts stand today, undoubtedly a great many students of average or more than average quality, as indicated by their marks, fail to see the complete unity of a concept that runs through the entire body of commercial law. It is true that careful teachers call attention to each instance of unity of concept, but pedagogical vigilance cannot wholly dispel the fog that hovers around all common principles of this type by reason of the multiplicity of uniform commercial statutes repeating identical rules in the same or slightly different form or setting forth rules that are distinguished by differences that are not useful.

The student passes to the bar and bench, and he continues to be enveloped by the fog which he has entered during his study of the branches of commercial law. As a lawyer and as a judge, he has no clear understanding of the unity of any of the great concepts of commercial law. He knows negotiable instruments as a separate subject, fenced in by a stone wall from all other subjects, for he has studied hundreds of cases illustrating and explaining certain principles purely as principles of negotiable instruments, and he knows sales and other commercial law subjects in a similar way; and now, at the bar or on the bench, helping to make precedent, he has no realization of the breadth of some of the most important rules that have governed commerce for centuries. That many lawyers and judges have failed to sense some of the clearest instances of unity of concept in different branches of commercial law is evident to any one who has read any number of judicial decisions in commercial branches, before and since the passage of the uniform statutes. Whether more judges clearly perceive a sure and undisputed unity of concept than perceived it a generation ago, is perhaps doubtful, for far from all of the cases of the past few years are reassuring as to such perception.

It is beyond the scope of this article to enumerate all of the principles common to the several branches of commercial law 
or even those common to the several uniform statutes referred to. We shall, however, notice briefly a few of the principles common. to the different subjects covered by the statutes or common to several of such subjects.

One of the most important instances of a principle common to every branch of commercial law is that of "fraud in the inducement" and "fraud in the execution," so well known in connection with negotiable instruments and so frequently lost sight of by judges and others in dealing with cases arising in sales and other commercial subjects.

"Fraud may induce a person to assent to do something which he would not otherwise have done, or it may induce him to believe that the act which he does is something other than it actually is. In the first case the act of the defendant is effectual though voidable; in the second case the act of the defrauded person is void because of his mistake. This distinction most commonly arises in the law of negotiable paper. It originated, however, in the law of sealed instruments; and is still of general application." 1

What constitutes "value," conferring upon the giver thereof the protection afforded a purchaser for value? This is a question arising in all branches of commercial law.

"There seems no reason to distinguish what constitutes value where negotiable paper is purchased and where property of other sorts is purchased. The purchaser for value of negotiable paper may get greater rights than the purchaser for value of property of other kinds, but it seems an unnecessary and undesirable complication of the law to maintain a distinction as to what constitutes value. This is especially true so far as chattel property is concerned, since such property is frequently transferred by means of bills of lading and warehouse receipts. In view of the large degree of negotiability given such documents, it would be unfortunate to distinguish them from negotiable paper in respect to the definition of value." 2

${ }^{2} 2$ Willistox, Sales (2d ed. 1924) \$625.

${ }^{2}$ Ibid. $\S 620$. 
Implied warranty of title is another principle pervading all subjects of commercial law covered by uniform statutes.

"The doctrine of implied warranty of title applies not simply to chattels but also to choses in action, both to those having tangible form, such as bonds, stock, negotiable paper, and also to those having no tangible form, such as accounts, reports of a commercial agency, rights in a partnership, and rights in inventions whether patented or not. In short, the doctrine is applicable to all personal property. Under the Sales Act, at least, an exchange is properly designated a sale, and even apart from statute there is the same warranty of title in a contract of barter as in a sale for money." 3

Already the rules as to warranty by the person negotiating or transferring for value a document of title, under the Uniform Sales Act, Section 36, closely approximate the rules laid down as to warranty by the qualified indorser of a negotiable instrument, in the Negotiable Instruments Law, Section 65. In fact the two lists of warranties are so similar that it would not seem impossible to formulate one acceptable statement of the warranties that should accompany negotiation in both types of case. Thus confusion and uncertainty could be avoided and the convenience of business served. Very similar are: the warranties on the sale of a stock certificate, as listed in the Uniform Stock Transfer Act, Section II ; the warranties on the sale of a warehouse receipt, as listed in the Uniform Warehouse Receipts Act, Section 44; and the warranties on the sale of a bill of lading, as listed in the Uniform Bills of Lading Act, Section 35. Several of these provisions as to warranty are common to all these acts and could be made to apply generally to commercial transactions of these various types.

In the table an attempt is made to show graphically just a few of the considerable number of principles that are common to two or more of the six uniform commercial statutes. It will be noticed that, in instances in which a given subject is not treated in all six statutes, its absence from one or more statutes does not necessarily make it less than general in its actual application or at least its perfectly proper application.

${ }^{3}$ I WILISTON, op. cit. supra note I, §2I8. 


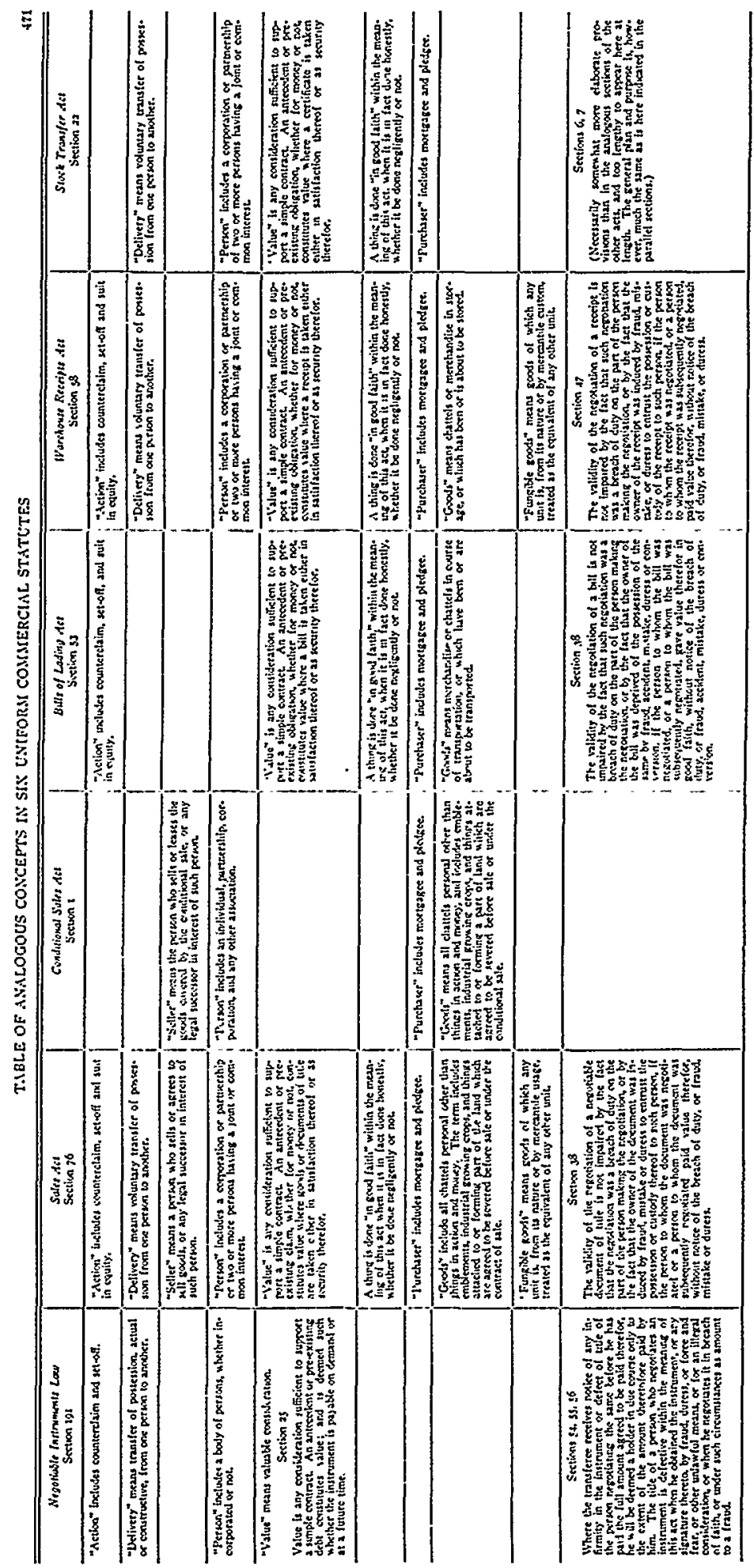



It would seem that the most useful framework of a uniform consolidated commercial law statute would be about as follows: part one, a complete statement of all the general provisions affecting all the subjects treated ; and part two, the special and particular matter on each subject in a chapter of its own, for instance, chapter one, negotiable instruments; chapter two, sales, etc.

Probably basic or radical changes in each subject will be neither necessary nor desirable. It is not our purpose here to suggest great changes in any branch of the law now covered by the uniform statutes. Greater clarity of meaning than is now possessed by some of the uniform laws might perhaps be achieved by demonstrating in a consolidated commercial statute that certain broad principles permeate the entire commercial law, without any fundamental changes within any subject.

Some of the principles common to all branches of commercial law, if stated separately for each branch, need a slight variation in statement under different subjects, as is shown by the differences in the last group of provisions stated in the table; but a large portion of the matter covered even in this group seems susceptible of being reduced to one common and general statement, with particular provisions under each particular heading to cover necessary variations or additions.

It cannot, of course, be said that the task of consolidating the six commercial statutes would be, in all aspects, simple; but it is believed that it is entirely possible so to formulate such a statute as greatly to improve and simplify the appearance of statutory commercial law. 